
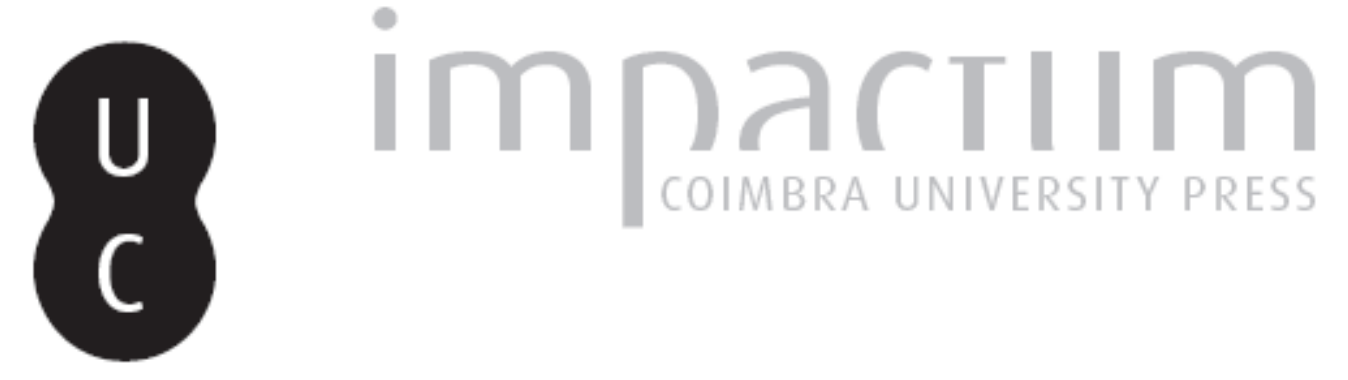

\title{
As Humanidades e a Universidade: crise e futuro
}

Autor(es): $\quad$ Souza, Maria Adélia de

Publicado por: Imprensa da Universidade de Coimbra

URL persistente:

URI:http://hdl.handle.net/10316.2/37826

DOI:

DOI:http://dx.doi.org/10.14195/0870-4112_3-1_2

Accessed : $\quad$ 26-Apr-2023 13:01:31

A navegação consulta e descarregamento dos títulos inseridos nas Bibliotecas Digitais UC Digitalis, UC Pombalina e UC Impactum, pressupõem a aceitação plena e sem reservas dos Termos e Condições de Uso destas Bibliotecas Digitais, disponíveis em https://digitalis.uc.pt/pt-pt/termos.

Conforme exposto nos referidos Termos e Condições de Uso, o descarregamento de títulos de acesso restrito requer uma licença válida de autorização devendo o utilizador aceder ao(s) documento(s) a partir de um endereço de IP da instituição detentora da supramencionada licença.

Ao utilizador é apenas permitido o descarregamento para uso pessoal, pelo que o emprego do(s) título(s) descarregado(s) para outro fim, designadamente comercial, carece de autorização do respetivo autor ou editor da obra.

Na medida em que todas as obras da UC Digitalis se encontram protegidas pelo Código do Direito de Autor e Direitos Conexos e demais legislação aplicável, toda a cópia, parcial ou total, deste documento, nos casos em que é legalmente admitida, deverá conter ou fazer-se acompanhar por este aviso.

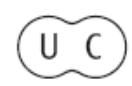




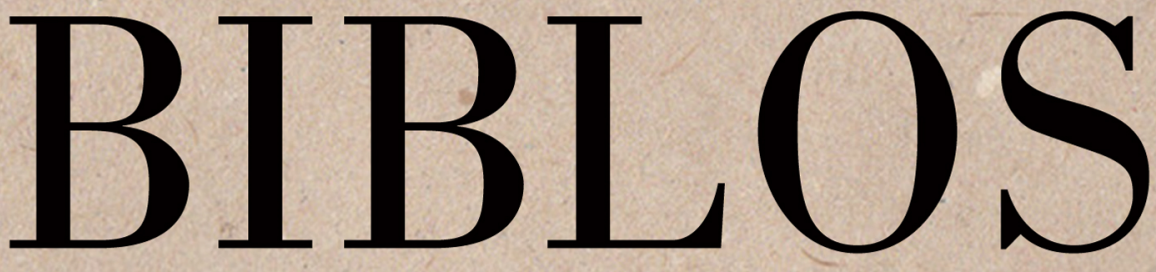

Revista da Faculdade de Letras da Universidade de Coimbra

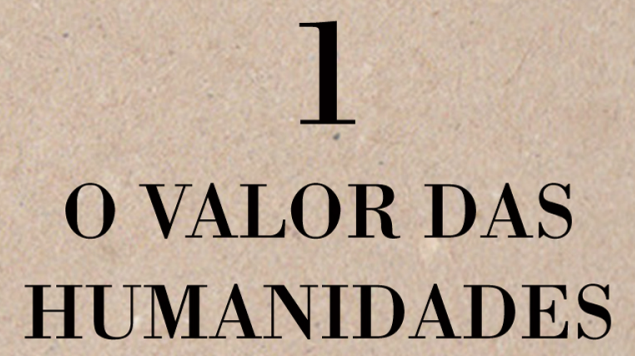

NÚMERO 1, 2015

3. ${ }^{\text {a }}$ SERIE 


\title{
AS HUMANIDADES E A UNIVERSIDADE: CRISE E FUTURO
}

\author{
The Humanities \\ and the University: \\ crisis and futur
}

\author{
MARIA ADÉLIA DE SOUZA \\ madelia.territorial@gmail.com \\ Universidade de Sáo Paulo
}

DOI

http://dx.doi.org/10.14195/0870-4112_3-1_2

Recebido em setembro de 2014

Aprovado em janeiro de 2015

Biblos. Número 1, 2015 • 3. a Série

pp. $31-56$ 


\title{
RESUMO.
}

Este artigo trata de compreender as HUMANIDADES neste período histórico respondendo a algumas questōes aqui formuladas. Aborda o sentido da tecnologia e os processos que gera no mundo, particularmente, nas universidades de países como o Brasil. Examina como a Universidade realiza seu trabalho científico cada vez mais tributário da técnica, e sua submissão às agendas das empresas. Quais as implicaçôes das Humanidades em nossas instituiçôes de ensino e pesquisa diante desse processo? Como compreender a prática das universidades com pesquisas vinculadas às inovaçôes tecnológicas em diferentes campos do saber técnico, com o objetivo de imaginar possível a aceleração da história atendendo aos desígnios do mercado? Como os países pobres enfrentarão essa necessidade de resgatar a história como processo e não apenas como presente? Como as Humanidades deixarão de ser tributárias desse pragmatismo exigido pela dinâmica acelerada do mundo para resgatarem o seu papel crítico diante do processo histórico?

Palavras-chave: Humanidades; Tecnologias; Interdisciplinaridade; Impasses da universidade; Brasil e produção do conhecimento.

\begin{abstract}
.
This article aims at understanding the Humanities in the current historical period. It addresses the question of the aim and purpose of technology and of its impact - particularly in Brazilian universities. It examines how the scientific work of the University is increasingly dependent on technology (which is itself in thrall to corporate agendas). What are the implications of this for research and teaching in the Humanities? How are we to understand the universities' practice of promoting, across a number of technological fields, research aimed at accelerating the pace of development in order to meet the demands of the market? How will poor countries be able to recover a sense of history as a process (evolving time, scale and social change)? Which methodological paths will set the Humanities free from a pragmatic compliance with the demands of such a world and enable the recovery of their role as a critic of the historic process?
\end{abstract}

Keywords: Humanities; Technologies; Interdisciplinary; University stalemates; Brazil and production of knowledge. 


\section{INTRODUÇÃO}

Há um debate importante sobre o sentido do mundo de hoje que precisa ser colocado, tanto em suas manifestaçôes gerais quando particulares para discutir sobre as Humanidades na Universidade. Neste texto, o objetivo é particularizar o debate sobre as humanidades no Brasil ${ }^{1}$.

Portanto, este artigo procurará desenvolver alguns princípios constituídos pela compreensão do mundo contemporâneo, do método e a questão da interdisciplinaridade. Em seguida, buscará pontuar o sentido das HUMANIDADES neste período histórico aqui denominado de técnico, científico e informacional, de modo a situar o Brasil no mundo. Será, então, necessário refletir e argumentar sobre o sentido das técnicas e que processos elas têm gerado no mundo e, particularmente, em um país como o Brasil, considerado um país emergente. Qual o enfrentamento que a Universidade precisa realizar a partir das complexidades apontadas?

Como a ciência produzida na Universidade, tributária da técnica e do mercado, explica sua submissão às agendas das empresas? Quais suas implicaçôes para o desenvolvimento das Humanidades em nossas instituiçôes universitárias? Então, precisaremos argumentar no sentido de compreender a obsessão das universidades dos países do sul, a exemplo do Brasil, por pesquisas vinculadas às inovaçôes tecnológicas em diferentes campos do saber técnico, especialmente nas engenharias, na medicina, na biologia, na química e na física. Um saber aplicado a um determinado objetivo que imagina possível a aceleração da história mediante tais procedimentos, nem sempre diretamente conectado ao atendimento direto das demandas sociais.

De todo modo, ao longo e ao término deste artigo, é preciso refletir sobre como as Humanidades enfrentarão essa imensa necessidade de resgatar a história como processo e não apenas como presente; e, de que maneira elas podem

\footnotetext{
A Faculdade de Filosofia, Letras e Ciências Humanas da Universidade de São Paulo realizou um colóquio intitulado Humanidades, pesquisa, universidade. Esta reflexão dá continuidade àquelas feitas por meu colega Milton Santos, publicadas pela Comissão de Pesquisa da Faculdade, em 1996.
} 
deixar de ser tributárias do pragmatismo exigido pela dinâmica acelerada do mundo, e resgatar seu papel crítico do processo histórico.

Aqui serão desenvolvidas algumas reflexóes e argumentos, com base nas questóes apontadas acima: primeiramente, examinando o sentido do mundo atual, seus problemas e desafios para os países pobres. Em segundo lugar, face a essas características, será possível situar as humanidades diante de um novo conceito de homem e de História. Introduzindo a questão das Humanidades, traremos um terceiro argumento: aquele que situa as Universidades e as tecnologias como tributárias do mercado. Em seguida, apresentamos um quarto argumento, referente a seus problemas e possibilidades, retomando uma ideia explorada no início do primeiro argumento, qual seja, o mundo como possibilidade de outra globalização.

\section{O SENTIDO DO MUNDO HOJE: PROBLEMAS E DESAFIOS PARA O MUNDO POBRE \\ O mundo de hoje se nos apresenta como fábula, como perversidade e como possibilidade de constituição de outra globalização (Santos 2000).}

Vivemos um mundo confuso e confusamente percebido. (...) De um lado, (...) o extraordinário progresso das ciências e das técnicas, das quais um dos frutos são os materiais artificiais que autorizam a precisão e a intencionalidade. De outro (...) aceleração contemporânea e todas as vertigens que cria, a começar pela própria velocidade. (...) Um mercado avassalador dito global é apresentado como capaz de homogeneizar o planeta quando, na verdade, as diferenças locais são aprofundadas. (...) no lugar do fim da ideologia proclamado pelos que sustentam a bondade dos presentes processos de globalização, não estaríamos, de fato, diante da apresentação de uma ideologização maciça, segundo a qual a realização do mundo atual exige como condição essencial o exercício de fabulaçôes. (Santos 2000: 17-19)

Milton Santos nos ensina, ainda, que para a maioria da população do globo, essa globalização nos é imposta como uma "fábrica de perversidades" 
(Santos 2000: 19). Suas consequências são os visíveis males físicos e morais que se amontoam, se alastram e se aprofundam como a fome, as doenças, as pandemias, os cinismos de toda ordem, a corrupção, os egoísmos.

Outro autor que possui uma visão crítica sobre as perversidades do mundo atual e nos remete às reflexôes de Hannah Arendt sobre a política e a mentira, é o espanhol Jose Carlos Bermejo.

La institucionalización y la consgración de la mentira son hoy posibles gracias a la creacion de los mecanismos de desinformación (...). Dichos mecanismos se basan em la acumulación, diseminación de datos y reiteración de lemas de forma insistente y massiva. Ello es posible gracias a la simplificación del pensamento y de la información, de la que son responsables los médios de comunicación y las instituciones educativas y para la que son imprescindibles las tecnologias de la información. Estas son instrumentos muy eficaces dentro de sus próprios limites, y pueden ser manejados com inteligência, o por el contrário convertirse em instrumentos de empobrecimento del conocimiento, que puden llegar a fomentar la própria incapacidade de pensar.

(Bermejo 2012: 17)

Este autor é um crítico contumaz do pacto de Bolonha e suas implicações na vida das universidades que o adotaram.

Outra globalizaçáo, no entanto, pode ser constituída a partir das condiçôes dadas pela dinâmica e funcionamento do mundo atual. Isto é a ciência, a técnica e a informação podem ser apropriadas não apenas pelo mercado, mas serem colocadas a serviço de um mundo melhor, mais justo, e que contemple a maioria pobre da população do planeta. Trata-se, portanto, de uma discussão essencialmente política sobre o sentido e significado do desenvolvimento tecnológico e seus objetivos essenciais e universais. Sobre isto nos alertava Ortega y Gasset (Ortega y Gasset 1998) com esta pergunta intrigante: "Por que o homem prefere viver a deixar de ser?" Com essa pergunta ele vai construir uma série de argumentos do abandono do homem de viver à base de instintos de conservação. Contudo, ele também coloca outra importante questão: por que normalmente o homem quer viver? Que empenho tem o homem em estar no 
mundo? Tais questões estão no fundamento de sua reflexão sobre a técnica e o esforço que a humanidade fará para estar no mundo; centrada na compreensão aprofundada do viver e do viver bem. Segundo esse autor, é no viver bem que o conceito de necessidade vai se transformando, alterado pelo desenvolvimento das técnicas no atendimento das necessidades básicas do homem para viver e viver bem: melhoria nas condiçôes de sua alimentação, do enfrentamento do frio e do calor, das possibilidades mais eficientes da sua mobilidade. Enfim, é a técnica e a tecnologia que vão determinar cada vez mais o modo de vida dos humanos na superfície da Terra. No entanto, a acessibilidade aos resultados do desenvolvimento tecnológico e do avanço das técnicas vem sendo subtraído da sociedade como um todo, e reservado às empresas e a minoria mais rica do mundo.

Milton Santos (Santos 2000) vai propor a possibilidade de pensarmos em uma globalização mais humana, a partir do seu motor de funcionamento, que é o desenvolvimento científico-técnico-informacional. Segundo Santos, os fundamentos disso seriam dados pelas bases materiais desta contemporaneidade, refletidas na unicidade da técnica, a convergência dos momentos e o conhecimento do planeta. Eis as bases do atual processo de globalização, utilizado pelo grande capital na construção das perversidades já apontadas. No entanto, concordamos com esse autor que a partir dessas mesmas características um novo mundo possa ser constituído desde que colocadas a serviço da humanidade a partir de novas bases políticas e sociais, ou a partir da possibilidade de discussão de um novo modelo civilizatório. Edgar Morin (Morin 1997) também compartilha dessa visão trazendo-nos questóes interessantes: "A mundialização ${ }^{2}$ corresponde ao surgimento de problemas comuns e específicos para toda humanidade. Mas a ideia de humanidade é rejeitada; muitas vezes considerada como obsoleta" (Morin 1997: 9). Também ensina que hoje a aspiração política é menos ingênua do que outrora, porém, sua amplitude provoca uma obra histórica de largo fôlego "que deveria se confundir com a aventura

2 Os franceses como é sabido preferem a palavra mundialização à globalização. 
humana: é uma tarefa essencial para melhorar as relaçóes entre os humanos, as relaçóes interpessoais, e até as relações na escala do planeta” (Morin 1997: 138).

No entanto, Milton Santos (Santos 2000), inspirado em Ortega y Gasset, aponta uma série de processos, passíveis de verificação empírica no mundo contemporâneo, emergências daquilo que ele denomina de nova História: primeiro, a enorme mistura de povos, uma sociodiversidade com sua "mistura" de filosofias de vida, em detrimento ao racionalismo europeu; a segunda é o acelerado processo de urbanização, caracterizado por um intenso processo de metropolização, ou seja, o direcionamento das populaçóes pobres para as grandes cidades, em busca de sobrevivência. Essa sociodiversidade é mais significativa do que a decantada biodiversidade vastamente defendida pelos ecologistas. É nesse movimento que se funda, para essa população de pobres, o discurso da "escassez" revelador de suas condiçóes de vida; contraponto definitivo do discurso tecnológico disseminado a partir das pesquisas universitárias aliadas das empresas.

Este discurso é a grande descoberta das massas (Ortega y Gasset 1926) que se constitui nas bases de um novo clamor político por elas expresso publicamente, abrindo a possibilidade de processos de resistência revelados em grandes manifestaçóes nas grandes cidades do mundo, especialmente por migrantes; sejam eles originados de processos de migração internacionais, como o caso francês, sejam dos migrantes pobres entre países latino americanos, como os bolivianos, peruanos, haitianos que chegam ao Brasil, ou nacionais, como aquele dos nordestinos brasileiros para o sudeste do país.

A verificação de uma história concreta acontecendo no presente exibe a possibilidade de produção pela sociedade de uma nova história. Este seria o grande fundamento de uma nova globalização. Esta proposição emerge do período histórico atual que é, ao mesmo tempo, uma crise. Por isso, todas as soluçóes apontadas, que não sejam estruturais, geram novas crises. A tirania do dinheiro e da informação é hoje legitimada pelo "pensamento único", hegemonizada, com usos extremados de técnicas e de normas. Por isso, a política acaba por se instalar em todos os espaços onde essa hegemonização não alcança em porçôes do território onde a vida pulsa longe desses processos ditos globalizados. Não há homogeneidade na difusão da 
globalização e da técnica. Aí residem os processos novos das possibilidades de outra globalizaçáo.

$\mathrm{Na}$ Geografia, a aplicação dos Sistemas de Informação Geográfica obscureceu o conceito e sentido básicos do espaço geográfico, que de instância e categoria de análise social, torna-se elemento formal de simples localização; onde o espaço geográfico é entendido como uma geometria. Conceito ultrapassado pela própria característica central da globalização que é a aceleração contemporânea e as possibilidades múltiplas de localização dadas pela difusão dos sistemas técnicos e tecnológicos.

Contrariamente ao que foi proposto por alguns autores, náo se trata do "fim da história", mas de um novo começo; certamente mais generoso e fundamentado em uma nova concepçáo de mundo que precisa ser cuidadosamente examinada, especialmente, pelas Humanidades.

As ideias aqui defendidas partem de uma nova epistemologia da Geografia, usando os novos conceitos de lugar e de território usado ou espaço banal, isto é, o território usado, praticado, que se confunde com a existência humana. Estes são manifestaçôes do espaço geográfico, aqui entendido como uma indissociabilidade entre sistema de objetos e sistema da açōes (Santos 1996b).

A introdução do espaço geográfico nesta discussão ajuda a encaminhar duas questôes importantes, para fundamentar uma retomada das discussóes sobre as Humanidades na Universidade. A primeira delas é que, a partir dos lugares, este espaço do acontecer solidário, em função de interesses múltiplos, se nos apresenta valendo-se inclusive de uma utilização própria da técnica. Mas, sobretudo, entre os pobres, a técnica tem possibilitado manifestaçóes que se caracterizam por um intenso processo de resistência fundado em uma nova Política, cimentada em função de valores de sobrevivência e de respeito à vida. Nesta realidade, aparentemente à parte, que existe nas periferias das grandes metrópoles, o futuro do mundo está sendo gerado, pois, uma reação

\footnotetext{
Lugar aqui entendido como um espaço do acontecer solidário, diferenciando daquele de localidade com o qual tem sido insistentemente confundido, ou mesmo com o nível local, agora muito em moda especialmente na Europa.
} 
profunda em relação à manutenção da vida nela pode ser constatada. Questóes e demandas objetivas são formuladas tanto para a definição de novas estratégias de sobrevivência, quanto para o encaminhamento do processo político. Trata-se de uma nova maneira de fazer política, que causa estranheza diante de certas afirmaçóes de intelectuais do Norte, como Rosanvallon (Rosanvallon 2011: 11), ao nos introduzir em seu mais recente livro, propondo que "A democracia afirma sua vitalidade como regime ao mesmo tempo em que ela se enfraquece como forma de sociedade".

A aspiração à ampliação das liberdades e a instauração de poderes que sirvam a vontade geral, fez vacilar os déspotas e mudou a face do globo. Mas esse povo político que impóe de maneira cada vez mais intensa sua marca, cada vez menos se constitui num corpo social. (...) Este esgarçamento da democracia é o fato maior do nosso tempo, portador de terríveis ameaças. (Rosanvallon 2011: 11, trad. autora)

Apesar de ainda desconhecer a democracia, os povos do Sul do mundo, valendo-se dos dispositivos tecnológicos que acessam, contrariamente ao que pretende demonstrar Rosanvallon, se iniciam na prática política, constituindo novas e surpreendentes solidariedades coletivas, com sucessos plausíveis e demonstráveis. As fabulações também existentes entre os pobres cada vez mais os tornam sujeitos da História. A América Latina tem sido uma demonstração cabal de que isso é possível. Basta estudar com profundidade e examinar os rumos de seus processos eleitorais e democráticos dos últimos 20 anos!

Daí a importância de explicitação tanto da visão de mundo do autor, do lugar e de onde fala. Aqui estamos apoiados em Silva:

A crítica do humanismo tradicional logrou perceber que a afirmação de universalidade como extensão formal do princípio da igualdade é inversamente proporcional à compreensão da qualidade histórica de uma verdadeira ordem igualitária. E isso ocorreu porque a constituição da universalidade, ou do humanismo universal, deu-se como um processo governado pela lógica da exclusão. Nessa direção tornam-se inseparáveis, nas tarefas que 
as Humanidades deveriam cumprir, a compreensão e a criação da ordem humana. Para isso é preciso abandonar a universalidade como forma $a$ priori e adotar a perspectiva de um conhecimento que seja ao mesmo tempo o resgate do seu objeto, os homens como sujeitos da ação histórica e protagonistas do drama da existência. E trata-se de um resgate necessário, pois o progresso civilizatório, que é tido como a grande realização do humanismo moderno, também pode ser visto como a exclusão progressiva das formas autênticas da experiência humana.

(Silva 2002: 19)

Os povos do Sul tributários que são das culturas cristãs e ocidentais começam, ainda que timidamente, a refletir sobre isso.

\section{AS HUMANIDADES, UMA VISÃO DE HOMEM E DA HISTÓRIA} As reflexóes deste item contêm um diálogo entre vários autores; mas foram sobremaneira importantes as reflexóes de Milton Santos (Santos 1996a), e aquelas de Franklin Leopoldo e Silva (Silva 2002). Este autor em sua Aula Inaugural da Faculdade de Filosofia, Letras e Ciências Humanas da Universidade de São Paulo, ministrada em 2001, nos instiga a mergulhar sobre esse tema quando nos sugere o seguinte questionamento: Como as Humanidades se comportam no estudo de um mundo complexo, com possibilidades de produção de objetos de múltiplas e diversas categorias, engendradas por esse emaranhado de técnicas disponíveis? Como as Humanidades hoje produzem uma visão de ser humano e de História?

Para Michel Foucault (Foucault 1983), o nascimento das ciências humanas e da filosofia moderna como saberes que atestam a invenção do conceito de homem, transformando o ser humano, ao mesmo tempo, em sujeito do conhecimento e objeto de saber se constitui no grande dogma da modernidade filosófica. Kant já nos havia alertado sobre esse dilema.

A história, ou seja,

as condições de existência dos homens no decorrer do tempo, que lhes escapa à consciência náo é da ordem da necessidade; ela diz respeito à 
liberdade, à invenção; pertence à ordem mais da casualidade do que da causalidade; é feita mais de rupturas e violência do que de continuidades conciliadoras. Esse modo de conceber a história se opóe à imagem tranquila que a narrativa histórica tradicional criou: a história do homem como a manifestação de um progresso inevitável — o lento processo de realização de uma utopia —, que seria alcançado após o iluminismo pela aplicação dos métodos racionais. Como se a ciência, o pensamento e a vida estivessem continuamente mais próximos de verdades que aos poucos são reveladas como o destino final do homem. ${ }^{4}$

Numa analogia a esta afirmação sobre a História, sabendo das possibilidades de sobreposição espaço/tempo dadas pelo funcionamento e disponibilidades dos sistemas técnicos atuais, podemos propor que a Geografia descritiva é a-histórica. Os fatos estão ali como milagres! Os fatos são descritos em função de sua localização estática, congelados no tempo. Limites de um conhecimento/saber que intervém decisivamente na ação/atuação dessa disciplina na perspectiva do resgate imprescindível das Humanidades na universidade. As geografias não são apenas formas, mas forma/conteúdo. Logo são históricas, produtos das relaçôes sociais e não apenas das dinâmicas e processos da natureza. Esta ambiguidade ainda existente na formulaçáo do conhecimento geográfico tem sido um entrave para que a maioria dos geógrafos participe desse fundamental debate sobre a importância das Humanidades na universidade. Mas tal não é a dificuldade daqueles que estáo mergulhados no conhecimento geográfico do mundo, através da Geografia Nova ${ }^{5}$.

O que interessa na propositura de Foucault é demonstrar o que suas pesquisas mostram: que nossas evidências são frágeis e nossas verdades, recentes e provisórias e que todo saber está ligado a um poder, e que todo poder se sustenta

\footnotetext{
4 Ver excelente matéria no sítio www.cartacapital.com.br (consultado em 31/07/2014).

5 Esta geografia se constitui em uma releitura epistemológica da "velha" Geografia realizada pelo geógrafo brasileiro Milton Santos. Ver Kitchin e Thrift (Kitchin, Thrift 2009).
} 
a partir de um saber, ou de um conjunto de saberes. E as Humanidades na Universidade têm tido dificuldades para acompanhar a dinâmica desse processo.

Mas o que é o Homem hoje? O que é o Brasil de hoje ${ }^{6}$ ?

O homem é aquele de Henri Lefebvre, o "Cibernantropo"; o "homem integral" de Merleau Ponty ou "o homem concreto" de Agnes Heller? Ou o homem dominado pela matéria trabalhada de Sartre, "homem produto de seu produto", da humanização desumana da materialidade, como nos ensina em sua importante reflexão para a Geografia nova, em que considera a "práxis" individual e o prático-inerte! (Sartre 1985: 295)? Ou, ainda, o homem separado do mundo pela alienação, traço característico da condição moderna, que assume proporçóes monstruosas nas décadas dos totalitarismos (1933-1953), segundo Hannah Arendt (Arendt 1972).

E de que Brasil trataremos aqui para ilustrar esta reflexão? O Brasil que conhece processos intensos de desigualdade socioespacial ou o Brasil das conveniências e dos discursos políticos? O Brasil "fácil" para tudo e para todos que vêm de fora? O Brasil que, malgrado os esforços realizados nos últimos anos, abriga desigualdades territoriais onde suas regióes Norte e Nordeste veem crescer o número de pobres e indigentes, a mortalidade de mulheres no puerpério? Ou o Brasil que conhece uma ampliação das desigualdades socioespaciais nas regióes metropolitanas?

Como as universidades estudam o avanço da democracia desmentida por esse avanço da pobreza e da violência? Falamos do Brasil superficial dos discursos políticos convenientes?

Assim também, o Brasil é objeto de estudos científicos atropelados pelo clamor da busca de novos paradigmas diante das ciências humanas completamente desprestigiadas como veremos mais adiante!

O desenvolvimento deste texto exibirá esse Brasil que convive com avanços tecnológicos em muitos setores e com a pobreza extrema em suas metrópoles e regiōes. Mas será esse o Brasil profundo, um "país fácil”, sem nenhuma Reflexôes formuladas por Milton Santos no colóquio Humanidades, pesquisa, universidade
organizado pela FFLCH da USP, aqui retomadas e desenvolvidas. 
possibilidade de formulação de seu próprio futuro? Será este presente caracterizado pela aceleração contemporânea, definido mais por metáforas do que por conceitos, onde a felicidade assumiu uma forma numérica e mensurável (Souza 2013), essa fábrica do medo, especialmente na cidade, como propóe Bauman (Bauman 2009), que determina o conhecimento nas ciências humanas?

Não seria interessante indagar à maioria da população pobre, qual é o seu medo? Considerá-la, em nossas reflexôes, como sujeitos da história, e não apenas a partir dos sujeitos da classe média que majoritariamente elaboram os estudos científicos?

Certamente suas respostas não coincidiriam com a visão da maioria dos intelectuais e com suas reflexóes sofisticadas e eruditas; visão equivocada e anódina, de que os tempos presentes possibilitam a "desterritorialidade", a insistência nas metáforas para designar processos do mundo. Vale aqui lembrar as reflexões sobre a forma e a causa, como sugere Cassirer, tão influenciadas pelos modelos universais da formulação do conhecimento planetário, porém excludente, e de uma informação universal, mas privilegiada e hegemonizada.

Bom é sempre recorrer a Nietzsche (Nietzsche 2004)7: "que o ser humano seja pretexto para algo que náo é mais ser humano" (Fragmento n. ${ }^{0} 4$, item 78 ). "Precisamos ser tanto cruéis quanto compassivos: evitemos tornar-nos menores que a natureza" (Fragmento n. ${ }^{\circ}$, item 79).

As Humanidades ficaram desprovidas do "humano" e aderiram às formulaçóes oportunistas exigidas pela racionalidade técnica, da qual passaram a ser tributária.

Fragmentos do espólio — julho de 1882 a inverno de 1883/1884, contem as anotaçóes de Nietzsche, como ele as escrevia. Cada fragmento, numerado é dividido em frases (ideias) colocadas entre parênteses e numeradas sequencialmente. Esta obra é diferente da outra, intitulada Fragmentos Finais, cujos fragmentos foram organizados por temas. Daí aquela aqui consultada, dar uma ideia de "fluxo caótico e saltitante da vida", conforme seu tradutor e prefaciador da obra, Prof. Flávio R. Kothe, da Universidade de Brasília. 


\section{A UNIVERSIDADE E A TECNOLOGIA: TRIBUTÁRIAS DO MERCADO}

Aqui resgatamos apenas sumariamente a reflexão sobre as implicações do advento da modernidade e sobre o que é o ser humano, para entáo chegar às reflexôes sobre a Universidade e a tecnologia nesta contemporaneidade.

Ao refletir sobre Humanidades e Humanismos, Franklin Leopoldo e Silva nos dá a dimensão da importância dessa reflexão.

Nós, que temos a consciência dividida entre a enormidade da tarefa e a intensidade do risco, sabemos, ou deveríamos saber, que a realidade náo se expóe com a facilidade do objeto constituído como uma paisagem à espera de contemplação; ou com a índole pacífica de uma exterioridade pronta para a assimilação. Sabemos que o conhecimento possui perfil dramático de todas as relaçóes humanas e que ele somente se torna humano quando atravessado pela consciência da incompletude presente nos nossos êxitos e nos nossos fracassos; quando sentimos a desproporção terrível entre o que identificamos como verdade e o campo infinito de obscuridade que se abre como horizonte que podemos divisar a partir de algumas certezas. O que nos distingue, é que somos impulsionados pela expectativa ansiosa daquilo que nos falta, mais do que lastreados pela tranquilidade orgulhosa do adquirido. (Silva 2002: 4)

Discorrendo sobre o mesmo tema, eis uma brilhante apresentação sobre as diferenças entre povos. Este é um fundamento importante a ser considerado na recuperação das Humanidades na constituição de um pensamento do Sul pelas universidades.

Uma sociedade, que tem questóes básicas a serem resolvidas pela maioria da sua população, como alimentação, habitação, saúde, educação, que expectativa deve ter de uma instituição a qual não tem acesso, nem pode se beneficiar de seus "produtos"?

No Brasil, as universidades e seus "produtos", cada vez mais são resultados de sua submissão às lógicas do mercado em todas as áreas, inclusive nas ciências humanas. Não pelo fato das pesquisas serem realizadas e cursos 
novos serem abertos em novas temáticas, mas pela forma como são tratados, estudados e ensinados. Enfim, pela constituição do seu Método. Um exemplo clássico, a ser mais estudado no Brasil, é aquele do turismo! Fantasias, metáforas e alienação definem a lida com essa importante temática produtora de recursos para muitas naçóes. No Brasil, multiplicam-se cursos de turismo em diferentes níveis; mestrados e doutorados ocos, sem método, imaginandonos numa Espanha ou um país europeu qualquer, onde o turismo seja sua importante fonte de riqueza nacional. Resultados no Brasil desse desvario acadêmico: porta aberta ao capital imobiliário, depredador dos nossos recursos naturais, especialmente nas praias; prática do turismo sexual envolvendo inclusive crianças menores; e todo tipo de perversidade que a modernidade tem a capacidade de produzir através da atividade denominada "turismo". Um tecnicismo e uma tecnicalidade submetida ao imediatismo favorecido pelos sistemas técnicos que precisam atuar nesta contemporaneidade para que o turismo funcione: as tecnologias da informação. Com isso, a aceleração contemporânea toma conta das mentes e das atividades e institui a racionalidade técnica.

Outro aspecto de interesse imediato das relaçóes entre sociedade e técnica, que Ortega y Gasset magistralmente nos chama a atenção, era sua suspeita de que náo apenas os engenheiros perderiam seu próprio controle sobre a produção das técnicas. Ele nos alerta para entender que a técnica não é a única coisa positiva, uma realidade irremovível do homem. Isto seria uma estupidez, pois, quanto mais os técnicos estejam cegos por ela, mais provável é que a técnica atual "se venga al suelo y periclite", para usar suas próprias palavras.

Além desse descontrole sobre seu próprio desenvolvimento que os engenheiros têm sobre ela - agora eles tornam-se também sujeitos subalternos do mercado. Basta para tanto, que se mude minimamente o perfil do bem-estar, para que tudo o que aí está fique completamente ultrapassado. A técnica mais que outra atividade humana se submete sensivelmente às características desta contemporaneidade, que é a aceleração contemporânea. Importante indicar aqui que inclusive as paisagens humanizadas estão a ela submetidas. O exemplo da derrubada das torres gêmeas do World Trade Center em New York é uma dessas possibilidades. Está comprovado que a técnica tem o enorme poder de 
mudar o mundo! Daí as Humanidades terem um papel central em seu estudo, compreensão e crítica.

Que universidade é essa e que Humanidades nós queremos ensinar?

Advogo a tese de que não é apenas a ciência e a técnica que são tributárias do mercado, mas também toda instituição universitária; tanto pelos temas e métodos que vem adotando, especialmente nas ciências humanas, que insistem em permanecer iluministas, logo, fora do seu tempo, quanto pelas práticas e temas que, sem nenhuma cautela ou pudor, começam a se institucionalizar, com claras vistas ao mercado.

$\mathrm{Na}$ Geografia Brasileira isso é rotina. Temas como gestão, turismo, sustentabilidade, literatura, para citar alguns deles são tratados de maneira travestida do ponto de vista metodológico. Não é o tema o assustador, mas a ausência do método geográfico no seu desenvolvimento. Sendo sinônimo de totalidade, o espaço geográfico por nós entendido como uma instância social, portanto, como espaço da existência, envolve a complexidade da vida humana.

Como já dissemos, descrever sem compreender se constitui numa das maiores fragilidades da geografia feita hoje no Brasil. E é importante dizer que somos tributários das escolas europeias no sentido mais amplo da palavra.

Ortega y Gasset (Ortega y Gasset 1998) ${ }^{8}$ nos faz refletir sobre o papel da universidade e da técnica; nesta relaçáo é que os problemas contemporâneos da universidade aparecem. Para o autor, ela "a universidade é um lugar de crime permanente e impune"; tema que impóe uma reflexão sobre as Humanidades e as instituições de ensino superior. Embora a técnica seja fator determinante na instituição da modernidade e desta contemporaneidade, ela apenas é estudada nas escolas e institutos especializados, mais vinculados ao fazer do que ao pensar.

Então, nas ciências humanas, o conhecimento sobre a técnica passa ao largo das preocupaçóes dos cientistas sociais. Como diz Ortega y Gasset, esse estado de coisas indica a convicção de que a técnica não diz respeito ao homem como tal, mas apenas a alguns aspectos particulares e secundários da vida.

\footnotetext{
8 Note-se que a primeira publicação deste texto é de 1933, produto de um curso ministrado pelo autor na Universidad de Verano de Santander, quando da sua inauguração.
} 
Assim, para este autor, a separação radical entre a universidade e as engenharias é uma das calamidades que implica nas imensas dificuldades que o homem enfrenta atualmente. Os engenheiros, em seu tecnicismo especializado, sem uma educação humanista e mais global, que somente a universidade pode oferecer-lhes, são incapazes de ajudar a solucionar e enfrentar os problemas que a técnica apresenta hoje para a humanidade. Um deles é aquele da guerra, cada vez mais tecnologicamente executada e administrada; o ponto de "os territórios" de declaração de guerra, com os respectivos "estados maiores", não ser mais necessários. A guerra espalha-se a qualquer instante e em qualquer lugar. E, se os motivos não existem, eles são criados, como nos revela José Carlos Bermejo (Bermejo 2012).

A falta de contato com a técnica transforma a universidade e, especialmente, as ciências humanas, em um dado abstrato, como quer Ortega y Gasset, sem vinculação possível com a vida real, impregnada de ciência, técnica e informação. A técnica, cujo papel essencial é resolver os problemas humanos, converteu-se em um novo e gigantesco problema.

Mas a técnica tem uma relação importante com as Humanidades, a partir do seu próprio conceito.

"La Tecnica es la reforma de la naturaleza, de esa naturaleza que nos hace necessitados y menesterosos; reforma en el sentido tal que las necessidades queden a ser possible anuladas por dejar de ser problema su satisfacción" (Ortega y Gasset 1998: 28). É este sentido de reforma da natureza e de criação de necessidades para viver e, posteriormente, viver bem, que a técnica se faz urgente no domínio das Humanidades. Para o atendimento de suas necessidades serão executados “atos técnicos”, especificamente humanos. É o conjunto desses atos técnicos, essencialmente humanos, que são desenvolvidos desde o inicio da humanidade, para que se possa aquecer, habitar, cultivar o campo e locomover. Todos estes "atos" tem um denominador comum, a saber, um procedimento que nos permite retirar da natureza tudo aquilo de que necessitamos para suprir essas necessidades, independentemente das circunstâncias em que vivamos. Eis aqui um problema sério que será, de forma cada vez mais aguda, colocado para a Humanidade ou Sociedade em que vivemos hoje. Ao conjunto de todos esses "atos técnicos" é que denominamos TÉCNICA. Mas, segundo 
Ortega y Gasset, não basta ao homem apenas viver. Ele quer viver bem. Eis o surgimento do complexo mundo das necessidades, tão bem explorado pela atual sociedade do consumo.

Mas a universidade, como tem resolvido essa questão? A universidade brasileira fez do chamado discurso político do desenvolvimento, vinculado à mágica palavra das "inovaçôes”, sua preocupação central. Isto se reflete na preocupação essencial com o ensino técnico, bem como com na abundância de recursos destinados às pesquisas em "inovaçóes tecnológicas”. Concordamos com a tese de que precisamos chegar ao presente do mundo, apesar de todos os problemas que temos. Mas como e a que preço! Se examinarmos, por exemplo, as informaçóes apresentadas a seguir, teremos fortes argumentos empíricos para esta tese. Trata-se da realidade brasileira, mas que, provavelmente, deve acontecer em vários outros países do mundo.

Examinando os dados para 2010 do Diretório de Pesquisa9 do CNPq - Conselho Nacional de Pesquisa do Brasil, constata-se, por exemplo, que quatro linhas de pesquisa do Diretório: produtos e processos biotecnológicos, desenvolvimento de novos materiais, neurociências e atividades no campo da nanotecnologia e desenvolvimento de nanoprodutos, que envolvem as ditas tecnologias de ponta, representam $31 \%$ do total de linhas de pesquisa catalogadas que correspondem a quase todo o universo das pesquisas científicas no Brasil. Se a isto acrescentarmos as pesquisas vinculadas à saúde humana, envolvendo a genética e aspectos correlatos, chega-se a quase 70\% do total de linhas de pesquisa financiadas pelo Conselho. Isto significa estímulo e uma maior quantidade de editoriais abertos para esse tipo de financiamento para as ditas "ciências duras".

O Diretório dos Grupos de Pesquisa no Brasil, projeto desenvolvido no CNPq desde 1992, constitui-se em bases de dados que contêm informaçôes sobre os grupos de pesquisa em atividade no País. O Diretório mantém uma Base corrente, cujas informaçôes são atualizadas continuamente pelos líderes de grupos, pesquisadores, estudantes e dirigentes de pesquisa das instituições participantes, e o CNPq realiza Censos bianuais, que são fotografias dessa base corrente. 
De qualquer maneira, um dado que chama a atenção é a comparação com os dados citados anteriormente, relativos às ditas "ciências moles", as Ciências Humanas, que representam apenas $16 \%$ do total de linhas de pesquisas, as Ciências Sociais Aplicadas, 10\% do total de linhas de pesquisa e a Linguística, Letras e Artes, 5\%. Comumente, no Brasil, as ciências ditas moles e seus cientistas não são levados a sério. Nossos trabalhos, nossas práticas e nossas tradiçóes críticas e livres são consideradas inadaptadas ao rigor que, segundo aqueles das áreas duras, seria necessário ao trabalho acadêmico e científico. Por outro lado, ainda em fase de constituição da sua própria identidade acadêmica e científica, as ciências sociais brasileiras são tributárias do conhecimento euro centrado, e caminham para a constituição de um conhecimento capaz de discutir questóes relevantes do processo de inovação e da própria política científica e tecnológica do país, sempre lideradas por colegas das "ciências duras". Além de um obstáculo inerente à nossa própria área, no sentido de dar-lhe maior densidade de conteúdos produzidos, temos um enorme obstáculo político para a valorizaçáo das Humanidades no processo de pensamento e de produçáo do conhecimento no Brasil.

Difícil imaginar que o pensamento crítico, sem a colaboração das Humanidades, seja realizado na maioria dessas pesquisas, pois sempre há uma esperança de que eles não sejam conduzidos apenas com interesses voltados para o mercado, mas também para a salvação material da humanidade. Um exercício interessante feito durante a elaboração deste artigo foi examinar os títulos e resumos dos artigos publicados pela Revista Brasileira de Inovação da Universidade Estadual de Campinas. Dentre eles, foi selecionado aquele de Schwartzman (Schwartzman 2002), cujas reflexóes buscam demonstrar o relacionamento entre a pesquisa científica e tecnológica no Brasil e o interesse público, nas áreas de pesquisa agrícola e ambiental, farmacêutica, e de ciências sociais. Apesar de seu título, em realidade esse trabalho procura examinar as relaçóes entre a pesquisa científica e o sistema produtivo, o que não significa o interesse público. Isso revela tão simplesmente a efetividade dos argumentos que apresentamos acima. Note-se que o autor deste artigo é um cientista social. Ele argumenta em ultima instância que o maior aliado da produção do conhecimento cientifico no Brasil, é o setor público e não o setor 
produtivo. Trata-se de um artigo escrito há mais de uma década. De lá para cá, a realidade mudou no que concerne ao financiamento da pesquisa, uma vez que os temas de maior interesse do setor produtivo têm sido financiados. E a destinação de recursos para as pesquisas diretamente vinculadas às empresas também passou a ser oferecida pelas agências financiadoras públicas. E isso só fez tornar ainda mais fraca a participação das Humanidades nesse processo financeiro e acadêmico.

Outra pesquisa que vem corroborar a discrepância dos investimentos em ciência e tecnologia no Brasil são os dados referentes à aplicação de recursos em 2013 pela FAPESP - Fundação de Amparo a Pesquisa do Estado de Sáo Paulo, a maior financiadora de pesquisa depois das agências nacionais ${ }^{10}$. Esses dados podem ser facilmente analisados, inclusive com séries temporais no sítio da fundação.

Importante, no entanto, destacar que náo se trata apenas de uma querela entre as ciências "duras" e as ciências "moles". Trata-se de uma discussão filosófica e objetiva sobre o sentido da inovação e da técnica na compreensão do mundo de hoje e das políticas que deveriam ser formuladas. É para esta tarefa que as Humanidades e todos os cientistas deveriam ser convocados. Mas caminhamos às cegas com relação ao nosso dilema: sermos "modernos" a qualquer preço ou permanecermos no passado? Porém, tal pergunta náo pode ser formulada de forma simplista, especialmente pelos "desenvolvimentistas" sempre táo ativos. Estamos diante de uma enorme complexidade para compreender o futuro do mundo, em que a universidade e as Humanidades sempre teráo um papel importante a desempenhar. A náo ser que reneguemos todos os pensadores do mundo que se dedicaram a refletir sobre tais temas, alguns dos quais têm sido recuperados neste artigo.

10 Esses dados podem ser facilmente obtidos, no sitio www.fapesp.br na janela de abertura, "Sobre a FAPESP" em Estatísticas e Balanços (consultado em 31/07/2014). 


\section{A UNIVERSIDADE E OS IMPASSES DAS HUMANIDADES: PROBLEMAS E POSSIBILIDADES}

Para Milton Santos, cujas reflexôes sobre este tema são fontes inesgotáveis de inspiração, nosso país ainda náo deixou crescer seus filósofos, pensadores, intelectuais. Lembra-nos ele que aquela "querela das Faculdades" discutida por Kant, hoje ganha uma nova importância e dimensão. Algumas Faculdades serviriam ao poder, ao Estado e ao Mercado. Outras, no entanto, efetuariam uma busca desinteressada pelo saber, detentora de uma força crítica com sua visão de futuro.

Nessa importante reforma no campo das ciências, e apesar do prejuizo que pode causar a razão especulativa nas posses que ela já se atribuiu até entáo, o interesse geral da humanidade [não foi afetado] e a utilidade que o mundo retirou até aqui das doutrinas da razão pura permanece a mesma de antes; o que há é o monopólio das escolas afetadas, mas absolutamente nada de interesses humanos. (Kant 1973: 87)

O estímulo a uma reflexão acerca da ação da razão sobre o conhecimento está maravilhosamente colocada na Crítica da Razáo Pura. "A primeira e a mais importante tarefa da filosofia é aquela de retirar de uma vez por todas desta dialética [entre a metafísica e dialética da razão pura] toda influência perniciosa destruindo toda verdadeira fonte de erros" (Kant 1973: 87-97, trad. da autora).

Em Metodologia da Razão Prática Pura (Kant 1983) Kant nos lança em uma discussão profunda sobre a virtude, a legalidade e a moralidade do conhecimento científico. Fonte de inspiração inesgotável para compreender os rumos que o conhecimento tem tomado nestes tempos obsessivamente dominados pelas "inovaçôes", este texto vê uma similitude das circunstâncias que eram por ele colocadas com relação à essência filosófica imposta, então, ao processo de conhecimento, à lida com a razão.

Que razão contemporânea é esta que retira "das escolas" a possibilidade crítica de compreender as consequências, para a humanidade, do processo de inovação? Razão quase que completamente nula de uma reflexáo crítica a ser realizada pelas Humanidades, tão desprestigiadas pela característica desse mesmo mundo onde o estímulo à produção ao conhecimento advém da busca 
a qualquer preço de financiamentos. Mercadores de pesquisa e suas respectivas corporaçóes percorrem o mundo inteiro, justificando recursos recebidos; aplicando-os aqui ou acolá; recapeando sempre seus próprios caminhos obscuros com relação às criticas que deveriam e poderiam fazer com o intuito de ajudar a humanidade a refletir sobre os "interesses humanos", como nos alertava Kant. Nas Humanidades, dadas as condiçôes atuais trazidas pelos processos técnicos, científicos e informacionais, é o futuro que já está dado, dependendo apenas de uma clareza de conhecimento e da escolha do futuro que desejamos. O passado como experiência foi substituído pela voracidade do tempo que nos impóe o futuro a cada instante! Este é um dilema que os tradicionais esquemas analíticos que ainda perduram nas ciências humanas não nos permitem avançar. Pode residir ai também o nosso papel cada vez menos relevante na table ronde das discussóes sobre o mundo. Comandado pelas inovaçóes e não pela dialética do mundo, seja a de Kant ou a de Marx, os interesses do mercado passam a ser mais importantes do que os "interesses humanos", os interesses pela vida.

Além dessas questóes essenciais, num país como o Brasil, na universalidade da ciência, no seu conteúdo e na sua prática, precisamos levar em consideração a existência de centros universitários dominantes e tributários, como diria também Milton Santos. "Nas ciências exatas, a universalidade das técnicas e dos interesses dominantes é servida por uma linguagem matemática unificadora que é, ao mesmo tempo, a-histórica e a-crítica. Essa universalidade é criada a priori” (Santos 1996a: 4).

Nas ciências sociais, para ser válida, a universalidade deve ser obtida a posteriori.

Mas o mundo vivido se apresenta como diverso já que os eventos, ontem e hoje, são prisioneiros do meio em que se dão. Essa comunicação local do mundo é filtrada pela cultura, por isso a diversidade das manifestaçóes autoriza diversas visôes e esquemas globalizadores todos válidos, cujo confronto ilumina o contexto global que se quer entender.

(Ortega y Gasset 2006: 4-5) $)^{11}$

11 Obra de Ortega y Gasset, extraída do sítio www.culturabrasil.org/rebeliaodasmassas.htm (consultado em 18/12/2006). 
Assim, na nova divisão intelectual do trabalho é esta visão dos processos globais que justifica as redes a que nos referimos; presididas por formulaçóes científicas a priori das ciências exatas. E delas, as Humanidades têm sido também tributárias.

\title{
CONSIDERAÇÓES FINAIS
}

As Humanidades, adaptando-se a esse modelo dito inovador e que funciona cada vez mais em redes, vão se tornando tributárias e não críticas a esse modelo, em que uma racionalidade ultrapassada, que persiste nas ciências exatas, não se aplica mais às ciências humanas; uma vez que o sentido, a dinâmica e a natureza do tempo social foram totalmente modificados, especialmente pela possibilidade de difusão da informação e, consequente comunicação dada pelos aparatos técnicos existentes, que evoluem aceleradamente a cada instante.

\begin{abstract}
A subordinação ao parâmetro tecnológico é assustadora, porque a técnica atual, impulsionada pelo mercado, acaba por impor sua própria teleologia, que é uma 'teleologia sem télos' (Rotenstreich). Quando a própria História (do Presente) é mostrada como se não fosse um sistema e como um acontecer sem finalidade é a ordem tecnológica que se impóe.
\end{abstract}

(Santos 1996a: 5)

No Brasil, a compreensão do sentido de modernidade - modernizaçóes sempre incompletas no nosso caso — vinculada a uma ambição produtivista, levou a universidade no âmago do seu labor, a realizar uma produção ampliada. O exemplo mais perverso disso é o quantitativismo nos processos de avaliação acadêmica que resulta do anteriormente citado pacto de Bolonha, criticado por Bermejo (Bermejo 2012).

Como o objetivo das Humanidades não é essa busca cega e desenfreada de resultados (presente nas publicaçóes científicas atuais, por vezes de uma mesmice superficial e ignóbil), elas se esqueceram de pensar o Futuro, no sentido das ações, o que as tornariam indispensáveis, pois conseguiriam dialogar com o produtivismo das "exatas". 
Portanto, nas Humanidades, temos que demonstrar qual nosso papel na construção do mundo novo que ai está. Seguirei as liçóes de Milton Santos: compreender refinadamente a perversidade da globalização; redescobrir o real significado das coisas, como desnudamento das imagens e a recuperação das identidades; reconhecer os limites da técnica como mediação universal; trabalhar a nova ideia de tempo - e, não confiar apenas nas mensagens das temporalizaçôes práticas, uma imposição do reino das necessidades; e apreender o presente como um conjunto sistêmico de todas as possibilidades atualmente existentes.

Como a técnica invadiu completamente a vida, esse reconhecimento do mundo necessita da elaboração de uma cultura técnica, como nos ensina G. Simondon, Jacques Ellul e muitos outros. Para tais autores, a cultura técnica é a base do novo humanismo e das novas Humanidades. Para Husserl, esta é a tentativa de "abstração em relação à subjetividade e à historicizaçâo", através da técnica.

Convém, como ensina Ortega Y Gasset, que o intelectual maneje e fique perto de todas essas coisas, das coisas materiais e das coisas humanas. Diz esse autor que, se os historiadores alemães do século xix tivessem sido mais homens políticos ou "homens do mundo", e se a história, em seu tempo, já fosse uma ciência e existisse uma técnica realmente eficaz para atuar sobre os grandes fenômenos coletivos, o homem atual não se encontraria, ainda, como no paleolítico, diante do raio.

$\mathrm{Ou}$, como diria Paul Virillo, urge reconhecer a negatividade da técnica, seus limites, mas também as possibilidades que abre para a construção de um novo mundo, de novas relaçôes sociais. Ou, conforme nos ensina A. Gras, que a tecnologia de ponta recria o artesão, como no sistema da aviação. A comunicação pode se transformar em elemento de comunhão. Essa re-humanização poderá ser estendida a outros ramos de atividade quando a sociedade humana for consciente do significado da técnica. Entáo o mundo aparecerá pleno de promessas e não apenas como uma ameaça.

E o Brasil deixará de ser um país "fácil", aonde muitos ainda vem nos "ensinar".

É assim, em busca desse caminho, que as Humanidades precisariam caminhar, ensinar e formular.

E esta tarefa é urgentíssima. 


\section{BIBLIOGRAFIA}

Arendt, Hannah (1972). Les origines du totalitarisme. Trad. P. Lévy. Paris: Gallimard.

Bauman (2009). Confiança e medo na cidade. Trad. Micheline Pouteau et alii. Rio de Janeiro: Zahar.

Bermejo, José Carlos (2012). La consagración de la mentira. Entre la realidade y el silencio. Madrid: Siglo XXI.

Foucault, Michel (1983). Estruturalismo e pós-estruturalismo ditos e escritos II, Arqueologia das Ciências e História dos Sistemas de Pensamento. Trad. Elisa Monteiro. Rio de Janeiro: Forense.

Kant, Emmanuel (1973). Critique de la raison pure. Préfaces et introduction. Trad. Alain Renaut. Paris: Aubier Montaigne.

Kant, Emmanuel (1983). Critique de la raison pratique. Trad. Alexis Philokenko. Paris: Librairie Philosophique J. Vrin.

Kitchin, Rob, Nigel, Thrift (2009). International Encyclopedia of Human Geography. Oxford: Elsevier. www.elsevier.com/books/international-encyclopedia-of-human-geography/kitchin/ (consultado em 31/07/2014).

Morin, Edgar, Naïr, Sami (1997). Pour une politique de civilisation. Paris: Arléa.

Nietzche, Friedrich (2004). Fragmentos do espólio. Trad. Flavio Rene Kothe. Brasília: Editora da Universidade de Brasília.

Ortega y Gasset, José (2006). A rebelião das massas. Trad. Herrera Filho. Edição Eletrônica: Ridendo Castigat Mores. Disponível em: www.ebooksbrasil.org/adobeebook/ortega.pdf (consultado em 18/12/2006).

Ortega y Gasset, José (1998). Meditación de la técnica y otros ensayos sobre ciência y filosofia. Madrid: Alianza Editorial.

Rosanvallon, Pierre (2011). La société des égaux. Paris: Éditions du Seuil.

Santos, Milton (1996a). "As humanidades, o Brasil, hoje: dez pontos para um debate", in Humanidades, pesquisa, universidade. São Paulo: Comissão de Pesquisa/FFLCH-USP, 9-13. Santos, Milton (1996b). A natureza do espaço. Técnica e tempo razão e emoção. Sáo Paulo: Hucitec. Santos, Milton (2000). Por uma outra globalização do pensamento único à consciência universal. Rio de Janeiro: Record.

Sartre, Jean-Paul (1985). Critique de la raison dialectique. Paris: Gallimard.

Schwartzman, Simon (2002). "A pesquisa científica e o interesse público”, Revista Brasileira de Inovação, 2, 1, 361-395. 


\section{MARIA ADÉLIA DE SOUZA}

Silva, Cylon Gonçalves da, Mello, Lucia Carvalho Pinto de, orgs. (2001). Ciência, Tecnologia e Inovação. Livro Verde. Brasília: Edição do Ministério da Ciência e Tecnologia e Academia Brasileira de Ciências.

Silva, Franklin Leopoldo e (2002). Humanidades e humanismos: a lógica da exclusão. São Paulo: SDI/FFLCH/USP.

Souza, Maria Adélia (2013). "Geografia, Paisagem e a Felicidade”, GeoTextos, 2, 9, 219-232. 